\title{
Thermogemmatispora onikobensis gen. nov., sp. nov. and Thermogemmatispora foliorum sp. nov., isolated from fallen leaves on geothermal soils, and description of Thermogemmatisporaceae fam. nov. and Thermogemmatisporales ord. nov. within the class Ktedonobacteria
}

Correspondence
Shuhei Yabe
kennan-6@kennan-e.co.jp

\author{
Shuhei Yabe, ${ }^{1}$ Yoshifumi Aiba, ${ }^{2}$ Yasuteru Sakai, ${ }^{1}$ Masaru Hazaka ${ }^{1}$ \\ and Akira Yokota ${ }^{2}$
}
${ }^{1}$ Hazaka Plant Research Center, Kennan Eisei Kogyo Co., Ltd, 44 Aza-Inariyama, Oaza-Ashitate, Murata-cho, Shibata-gun, Miyagi 989-1311, Japan
${ }^{2}$ Institute of Molecular and Cellular Biosciences, The University of Tokyo, 1-1-1 Yayoi Bunkyo-ku, Tokyo 113-0032, Japan

Currently, the phylum Chloroflexi is divided phylogenetically into the classes Chloroflexi (Garrity \& Holt, 2001), Caldilineae (Yamada et al., 2006), Thermomicrobia (Hugenholtz \& Stackebrandt, 2004), Anaerolineae (Yamada et al., 2006) and 'Dehalococcoidetes' (Hugenholtz \& Stackebrandt, 2004) and a class-level clone cluster of uncultured bacteria (Morris et al., 2004). The class Ktedonobacteria, which contains two cultured species with the validly published names, Ktedonobacter racemifer (Cavaletti et al., 2006) and

The GenBank/EMBL/DDBJ accession numbers for the $16 \mathrm{~S}$ rRNA gene sequences of strains $\mathrm{ONI}-1^{\top}$ and $\mathrm{ONI}^{\top}{ }^{\top}$ are $\mathrm{AB} 547912$ and AB547913, respectively.

A supplementary table is available with the online version of this paper.
Thermosporothrix hazakensis, was recently affiliated with the phylum Chloroflexi by Yabe et al. (2010a). Ktedonobacter and Thermosporothrix form branched substrate and aerial mycelia with spores and the colony morphology of the organisms is very similar to that of aerial mycelium-forming actinomycetes. Sporulation of Thermosporothrix hazakensis SK20$1^{\mathrm{T}}$ has been observed by scanning and transmission electron microscopy of cells grown at different stages of incubation by Yabe et al. (2010b); multiple exospores in each mother cell were formed by budding on the branched aerial mycelium. Spores originated from a lateral position in the mycelium. Although branched aerial mycelium is a characteristic feature of actinomycetes, multiple budding sporulation has not been described previously for prokaryotes (Yabe et al., 2010b). 
We isolated two novel thermophilic bacteria from fallen leaves on geothermal soils that form branched aerial mycelium and belong to the phylum Chloroflexi. To determine the taxonomic and phylogenetic position of these organisms, we examined their morphological, physiological, biochemical and chemotaxonomic characteristics and 16S rRNA gene sequences. The results indicated that these strains should be placed in two novel species of a new genus belonging to a new family and order of the class Ktedonobacteria.

We sampled fallen leaves deposited on steaming soil (60$90{ }^{\circ} \mathrm{C}$ at $10-15 \mathrm{~cm}$ depth) at Jigokudani in Onikobe Hot Springs, a geothermal area in Miyagi Prefecture, Japan. The samples were collected in a plastic bag (Ziploc), transported to the laboratory and stored at room temperature for 2 days.

We used a modified FS1V medium (MFS) for isolation, in which FS1V medium was supplemented with $100 \mathrm{mg}$ kanamycin $1^{-1}$ and $1 \%(\mathrm{w} / \mathrm{v})$ microcrystalline cellulose (Stott et al., 2008). The isolation medium was adjusted to pH 7.0 with $\mathrm{NaOH}$ at room temperature. Fallen leaves were spread on the plates and incubated at $65{ }^{\circ} \mathrm{C}$ for 3 weeks. Two colonies that formed aerial mycelium were selected and serially diluted in saline solution and the dilutions were then plated. Each single colony was purified by plating three times. Colonies were restreaked and each stock culture was prepared by inoculating agar slants from the second plate. The isolates were designated strains ONI$1^{\mathrm{T}}$ and ONI- $5^{\mathrm{T}}$.

Colony characteristics were determined after growth for 14 days at $65{ }^{\circ} \mathrm{C}$ on $\mathrm{FS} 1 \mathrm{~V}$ medium and International Streptomyces Project (ISP) medium 1 and 3 agar (Shirling \& Gottlieb, 1966) by visual inspection. Morphology of cells grown at $60{ }^{\circ} \mathrm{C}$ for 14 days on FS1V medium was examined using a phase-contrast microscope. Suitable agar blocks including colonies of ONI- $1^{\mathrm{T}}$ and ONI- $5^{\mathrm{T}}$ grown at $60{ }^{\circ} \mathrm{C}$ for 5 or 14 days on FS1V medium were subjected to scanning electron microscopy (SU8000; Hitachi). For transmission electron microscopy, suitable agar blocks including colonies of ONI- $1^{\mathrm{T}}$ and ONI- $5^{\mathrm{T}}$ grown at $60{ }^{\circ} \mathrm{C}$ for 10 days on FS1V plates were used. These were cut using an ultramicrotome into $80-90 \mathrm{~nm}$ slices, triple-stained with tannic acid, uranyl acetate and lead citrate and observed and photographed using a JEOL JEM1200EX electron microscope at an acceleration voltage of $80 \mathrm{kV}$. Scanning and transmission electron microscopy methodologies were as described previously (Yabe et al., 2010a).

Strains ONI- $1^{\mathrm{T}}$ and ONI- $5^{\mathrm{T}}$ grew well on FS1V medium and ISP1 agar and grew weakly on ISP3 agar. Strain ONI$5^{\mathrm{T}}$ developed orange colonies on ISP1 agar, whereas colonies of strain ONI-1 ${ }^{\mathrm{T}}$ were white. Aerial mycelium of these strains was observed on FS1V medium, but the strains did not form aerial mycelium on ISP1 or ISP3 agar.

Phase-contrast microscopy showed that strains ONI- $1^{\mathrm{T}}$ and ONI $-5^{\mathrm{T}}$ formed vegetative and aerial mycelia in FS1V medium and that both were irregularly branched and had morphology similar to that of common actinomycetes. Spores exhibited refractivity under the phase-contrast microscope. They were formed by budding on the aerial mycelium (Fig. 1a, c; arrows); mature spores were 1.0 $2.0 \mu \mathrm{m}$ long and $0.5-1.5 \mu \mathrm{m}$ in diameter (Fig. $1 \mathrm{~b}$, d), covered with a double membrane and surrounded by thick cell walls (Fig. 1e, g). As shown in Fig. 1(f, h), the strains formed two or more spores in a mother cell. These morphological features are similar to those of Thermosporothrix hazakensis SK20-1 ${ }^{\mathrm{T}}$ (Yabe et al., 2010b). The spores were oval in shape and had rough surfaces (Fig. 1a-d).

To determine the effects of $\mathrm{pH}$, temperature and $\mathrm{NaCl}$ concentration on growth, strains ONI- $1^{\mathrm{T}}$ and ONI- $5^{\mathrm{T}}$ were cultivated in ISP1 medium. Temperature, $\mathrm{pH}$ and $\mathrm{NaCl}$ concentration tests were performed at $40-80{ }^{\circ} \mathrm{C}(\mathrm{pH} 7.0)$, $\mathrm{pH} 3.0-8.7\left(60{ }^{\circ} \mathrm{C}\right)$ and $0-3 \%(\mathrm{w} / \mathrm{v}) \mathrm{NaCl}\left(60^{\circ} \mathrm{C}, \mathrm{pH} 7.0\right)$. The $\mathrm{pH}$ was adjusted with $\mathrm{HCl}$ and $\mathrm{NaOH}$ at room temperature. Anaerobic growth was observed in test tubes by adding $0.1 \%$ (w/v) $\mathrm{NaNO}_{3}, \mathrm{Na}_{2} \mathrm{SO}_{3}, \mathrm{NaNO}_{2}$ or $\mathrm{Na}_{2} \mathrm{~S}_{2} \mathrm{O}_{3}$ to ISP1 medium where air was replaced with $\mathrm{N}_{2}$. Assimilation of various sole carbon sources $(0.5 \%)$ (Larabinose, D-xylose, D-glucose, D-fructose, sucrose, Lrhamnose, raffinose, inositol and D-mannitol) was assessed using FS1V medium containing agar in place of gellan gum as a solidifying agent (FS1V agar) and determined to be positive or negative by the method reported by Shirling \& Gottlieb (1966). Hydrolysis of microcrystalline cellulose (Avicel), CM-cellulose, xylan, chitin, starch, gelatin and casein was evaluated using ISP1 agar supplemented with each substrate at a concentration of $0.5 \%(\mathrm{w} / \mathrm{v})$. The presence of a clear zone around the colony indicated that hydrolysis had occurred. Catalase activity was detected by bubble production in a $3 \%$ hydrogen peroxide solution. Gram staining was performed using the modified Hucker method (Smibert \& Krieg, 1994).

Strains ONI- $1^{\mathrm{T}}$ and ONI- $5^{\mathrm{T}}$ stained Gram-positive. Strain ONI- $1^{\mathrm{T}}$ grew at $50-74{ }^{\circ} \mathrm{C}$ and strain ONI- $5^{\mathrm{T}}$ grew at $45-$ $74{ }^{\circ} \mathrm{C}$; both strains showed optimum growth at $60-65{ }^{\circ} \mathrm{C}$. No growth of either strain was observed below 45 or above $78{ }^{\circ} \mathrm{C}$. The strains were able to grow at $\mathrm{pH} 4.6-8.0$ with an optimum $\mathrm{pH}$ of 7.0; no growth was observed at $\mathrm{pH} 4.0$ or below or at $\mathrm{pH} 8.7$ or above. The strains did not require $\mathrm{NaCl}$ for growth. Strain ONI-1 ${ }^{\mathrm{T}}$ grew in the presence of $1 \% \mathrm{NaCl}$, whereas strain ONI- $5^{\mathrm{T}}$ did not. No growth of strain ONI- $1^{\mathrm{T}}$ was observed at $2 \% \mathrm{NaCl}$. Both strains grew only under aerobic conditions. Strain ONI- $1^{\mathrm{T}}$ utilized Dxylose, D-glucose, sucrose, L-rhamnose and D-mannitol as sole carbon sources and hydrolysed gelatin, Avicel, CMcellulose, xylan and chitin but not starch or casein. Strain ONI- $5^{\mathrm{T}}$ utilized D-mannitol as a sole carbon source and hydrolysed Avicel, CM-cellulose, xylan and chitin but not gelatin, starch or casein. Both strains grew well in FS1V medium but not on FS1V agar.

Cellular fatty acids from strains ONI- $1^{\mathrm{T}}$ and ONI $-5^{\mathrm{T}}$ were prepared from cells grown on ISP1 medium for 7 days at 

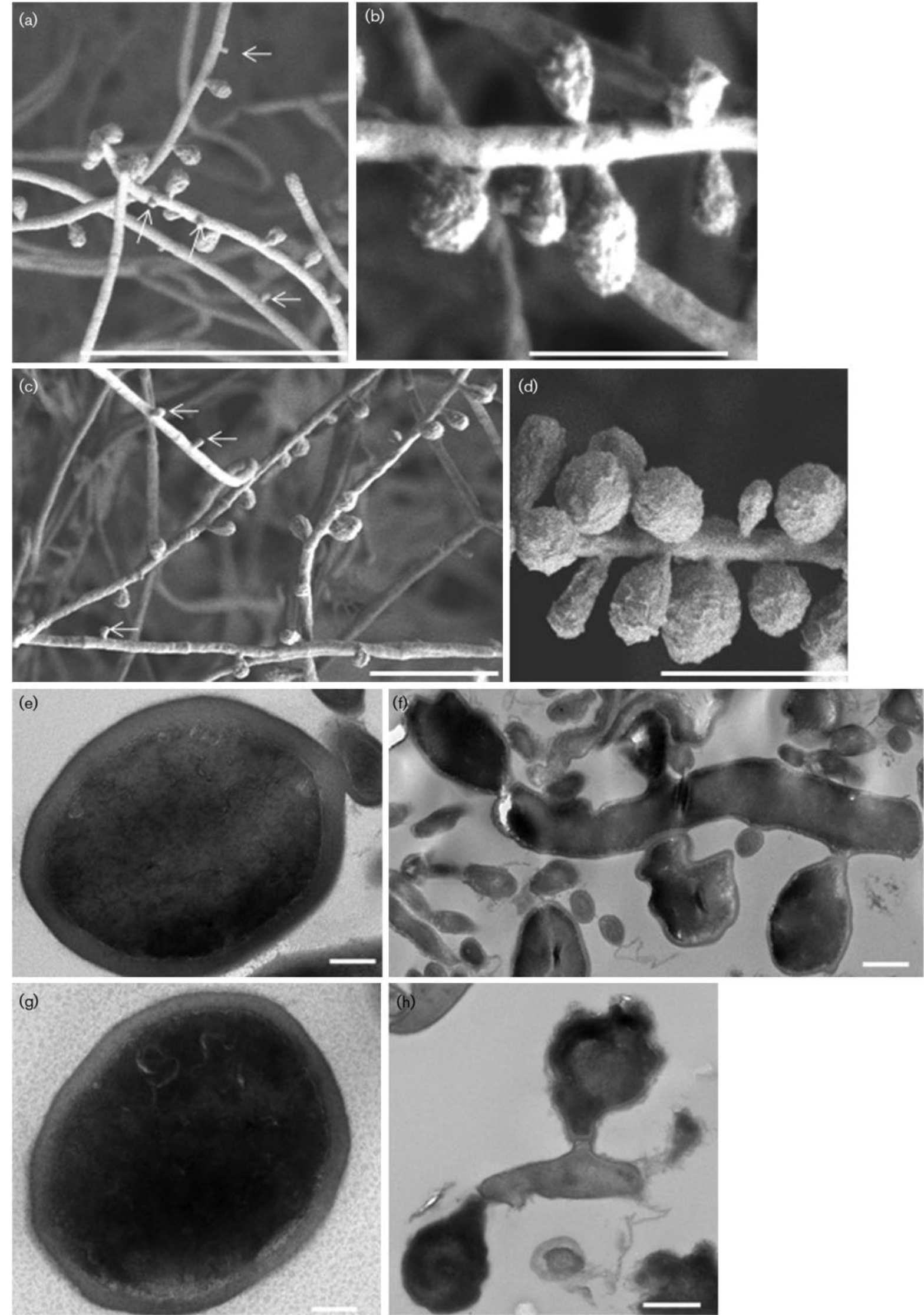
Fig. 1. Photomicrographs of cells of strains $\mathrm{ONI}-1^{\top}$ and $\mathrm{ONI}-5^{\top}$. (a-d) Scanning electron micrographs of strains $\mathrm{ONI}-1^{\top}(a, b)$ and ONI- $5^{\top}$ (c, d). Bars, $10 \mu \mathrm{m}$ (a), $2 \mu \mathrm{m}$ (b), $5 \mu \mathrm{m}$ (c) and $3 \mu \mathrm{m}$ (d). (e-h) Transmission electron micrographs of ultrathinsectioned cells of strains $\mathrm{ONI}-1^{\top}(e, f)$ and $\mathrm{ONI}^{\top} 5^{\top}(g, h)$. Bars, $500 \mathrm{~nm}(e, g)$ and $100 \mathrm{~nm}(\mathrm{f}, \mathrm{h})$.

$60{ }^{\circ} \mathrm{C}$ and then separated and identified using a commercial microbial identification system (MIDI Inc.). An unidentified fatty acid methyl ester peak was analysed further using a GC-mass spectrometer (GC-17A/GCMSQP5050). Cell walls were prepared using the methods described by Schleifer \& Kandler (1972) and amino acids in the cell-wall hydrolysate were identified by TLC (Harper \& Davis, 1979) and HPLC as phenylthiocarbamoyl derivatives using an HPLC apparatus (LC-10AD; Shimadzu) equipped with a Wakopak WS-PTC column (Wako Pure Chemical Industries) as described by Yokota et al. (1993). Cell-wall sugars were determined as alditol acetate derivatives by GLC using a Shimadzu GC-17A GC equipped with an Rtx $2330(0.32 \mathrm{~mm} \times 30 \mathrm{~m})$ column. Phospholipids were extracted and identified by twodimensional TLC and then sprayed with appropriate detection reagents based on the method reported by Tindall (1990a, b). Genomic DNA of the strains was prepared using a method modified from Marmur (1961) in which achromopeptidase and lysozyme (final concentrations 0.5 and $0.75 \mathrm{mg} \mathrm{ml}^{-1}$, respectively) were used for cell lysis. RNA was digested with a mixture of RNase A and RNase $\mathrm{T}_{1}\left(50 \mu \mathrm{l} \mathrm{ml} \mathrm{m}^{-1}\right.$; Wako). The $\mathrm{G}+\mathrm{C}$ content of genomic DNA was determined by HPLC (Tamaoka \& Komagata, 1984) using a Cosmosil 5C 18 -AR-II packed column $(4.6 \times 250 \mathrm{~mm}$; Nacalai Tesque $)$ with a DNA-GC kit (Yamasa Corp.).

The $\mathrm{G}+\mathrm{C}$ contents of strains $\mathrm{ONI}-1^{\mathrm{T}}$ and $\mathrm{ONI}-5^{\mathrm{T}}$ were 60.2 and $58.1 \mathrm{~mol} \%$, respectively, as determined by HPLC analysis (Table 1). The predominant menaquinone was MK-9 $\left(\mathrm{H}_{2}\right)$ and the major fatty acids were iso- $\mathrm{C}_{17: 0}(44.1 \%$ for strain ONI- $1^{\mathrm{T}}$ and $44.8 \%$ for ONI- ${ }^{\mathrm{T}}$ ), iso- $\mathrm{C}_{19: 0}(19.3$ and $27.3 \%$ ) and an unknown fatty acid [equivalent chainlength (ECL) of 19.032; 26.6 and 14.6\%]. Electron-impact MS of the unknown fatty acid ECL 19.032 was characterized by the presence of $m / z 326$ (molecular ion peak, M), $297(\mathrm{M}-29), 283(\mathrm{M}-43), 199,143\left[\mathrm{CH}_{3} \mathrm{CO}(\mathrm{CH})_{6}\right], 87$ $\left[\mathrm{CH}_{3} \mathrm{OC}(\mathrm{OH})-\mathrm{CH}-\mathrm{CH}_{2}\right]$ and $74 \quad\left[\mathrm{CH}_{3} \mathrm{OC}(\mathrm{OH})=\mathrm{CH}_{2}\right]$, which suggests that the unknown fatty acid corresponds to $C_{20: 0}$ methyl ester. The compositions of cellular fatty acids are shown in Supplementary Table S1, available in IJSEM Online. The polar lipids of the strains consisted of phosphatidylinositol, phosphatidylglycerol and a glycolipid (Table 1). The peptidoglycan of the strains contained glutamic acid, serine, glycine, histidine, alanine and ornithine in molar ratios of $1.0: 0.8: 2.5: 2.2: 2.2: 1.2$ in strain ONI- ${ }^{\mathrm{T}}$ and $1.0: 1.2: 2.6: 1.8: 2.5: 1.0$ in strain ONI$5^{\mathrm{T}}$. It is rare to observe histidine in a cell-wall peptidoglycan. The only cell-wall sugar in these strains was rhamnose. Differential chemotaxonomic and phenotypic characteristics of strains ONI- $1^{\mathrm{T}}$ and ONI- $5^{\mathrm{T}}$, T. hazakensis SK20-1 ${ }^{\mathrm{T}}$ and K. racemifer SOSP $1-21^{\mathrm{T}}$ are summarized in Table 1.
Almost-complete 16S rRNA gene sequences from these strains were amplified by PCR and the purified PCR products were sequenced as described previously (Yabe et al., 2010a). The 16S rRNA gene sequences of strains ONI- $1^{\mathrm{T}}$ and ONI-5 $5^{\mathrm{T}}$ were compared with sequences obtained from GenBank. Multiple alignments of the sequences were performed using CLUSTAL W (version 1.83; Thompson et al., 1994), and gaps and unidentified base positions were edited using BioEdit (Hall, 1999). Phylogenetic trees were constructed using the maximumlikelihood method (Felsenstein, 1981) in PhyML (Guindon \& Gascuel, 2003) and the neighbour-joining (Saitou \& Nei, 1987) and maximum-parsimony (Fitch, 1971) methods in MEGA version 4.1 (Tamura et al., 2007) with bootstrap values based on 100, 1000 and 1000 replications, respectively (Felsenstein, 1985). Evolutionary distances were computed using Kimura's two-parameter method (Kimura, 1980).

In the class Ktedonobacteria, two cultured species with validly published names are currently known, Ktedonobacter racemifer and Thermosporothrix hazakensis. The closest strain to strains $\mathrm{ONI}-1^{\mathrm{T}}$ and $\mathrm{ONI}-5^{\mathrm{T}}$ was $T$. hazakensis SK20-1 ${ }^{\mathrm{T}}$, with 85.3 and $84.5 \%$ 16S rRNA gene sequence similarity, respectively. $16 \mathrm{~S}$ rRNA gene sequence similarities of strains $\mathrm{ONI}-1^{\mathrm{T}}$ and $\mathrm{ONI}-5^{\mathrm{T}}$ to $\mathrm{K}$. racemifer SOSP $1-21^{\mathrm{T}}$ were respectively 83.1 and $83.0 \%$. Although these similarities are quite low, the morphology of strains ONI- $1^{\mathrm{T}}$ and $\mathrm{ONI}-5^{\mathrm{T}}$, which exhibit aerial and vegetative mycelia as well as spores, is similar to that of $K$. racemifer SOSP $1-21^{\mathrm{T}}$ and T. hazakensis SK20-1 ${ }^{\mathrm{T}}$. As shown in Fig. 2, the bootstrap support for the node of the class Ktedonobacteria is $100 \%$ according to the maximum-likelihood, neighbour-joining and maximum-parsimony methods, suggesting that strains $\mathrm{ONI}-1^{\mathrm{T}}$ and $\mathrm{ONI}-5^{\mathrm{T}}$ belong to the class Ktedonobacteria. Strains $\mathrm{ONI}-1^{\mathrm{T}}$ and $\mathrm{ONI}-5^{\mathrm{T}}$ are also present in the 'GS cluster' described previously by Yabe et al. (2010a); the cluster was formed at a high bootstrap value of $100 \%$. The cluster Ktedonobacteria is subdivided into two major clusters (Ktedonobacterales and GS). Furthermore, K. racemifer SOSP $1-21^{\mathrm{T}}$ and T. hazakensis SK20-1 ${ }^{\mathrm{T}}$ are divided at the family level in the Ktedonobacterales cluster. Therefore, the Ktedonobacterales and GS clusters, including strains ONI- $1^{\mathrm{T}}$ and ONI- $5^{\mathrm{T}}$, should be divided at the order level.

Strains ONI- $1^{\mathrm{T}}$ and ONI- $5^{\mathrm{T}}$ can be differentiated from other species of the Ktedonobacteria by the following chemotaxonomic characteristics. Strains ONI- $1^{\mathrm{T}}$ and $\mathrm{ONI}-5^{\mathrm{T}}$ have $\mathrm{C}_{20: 0}$ (ECL 19.032) as a cellular fatty acid and do not have diphosphatidylglycerol as a polar lipid. The peptidoglycans of strains ONI- $1^{\mathrm{T}}$ and ONI- $5^{\mathrm{T}}$ contain histidine.

Operational taxonomic units in the GS cluster in addition to strains ONI- $1^{\mathrm{T}}$ and $\mathrm{ONI}-5^{\mathrm{T}}$ consist of four cultivated strains (Chloroflexi bacteria P359, P352, T81 and T104) isolated 
Table 1. Characteristics of strains $\mathrm{ONI}-1^{\top}$ and $\mathrm{ONI}-5^{\top}$ and related type strains

Data for reference strains were taken from Yabe et al. (2010a) (T. hazakensis SK20-1 ${ }^{\mathrm{T}}$ ) and Cavaletti et al. (2006) (K. racemifer SOSP1-21 ${ }^{\mathrm{T}}$ ). All four strains stain Gram-positive and have MK- $9\left(\mathrm{H}_{2}\right)$ as the major quinone. ND, No data available.

\begin{tabular}{|c|c|c|c|c|}
\hline Characteristic & Strain ONI-1 ${ }^{\mathrm{T}}$ & Strain ONI-5 ${ }^{\mathrm{T}}$ & T. hazakensis SK20-1 ${ }^{\mathrm{T}}$ & K. racemifer SOSP1-21 ${ }^{\mathrm{T}}$ \\
\hline Colony colour on ISP1 agar & Orange & White & White & ND \\
\hline DNA G $+\mathrm{C}$ content $(\mathrm{mol} \%)$ & 60.2 & 58.1 & 54.0 & 53.9 \\
\hline \multicolumn{5}{|l|}{ Growth in the presence of: } \\
\hline $1 \% \mathrm{NaCl}$ & + & - & + & + \\
\hline $2 \% \mathrm{NaCl}$ & - & - & - & + \\
\hline Range & $50-74$ & $45-74$ & $31-58$ & $17-40$ \\
\hline Optimum & $60-65$ & $60-65$ & 50 & $28-33$ \\
\hline \multicolumn{5}{|l|}{$\mathrm{pH}$ for growth } \\
\hline Range & $4.6-8.0$ & $4.6-8.0$ & $5.4-8.7$ & $4.2-7.2$ \\
\hline Optimum & 7.0 & 7.0 & 7.0 & 6.0 \\
\hline \multicolumn{5}{|l|}{ Hydrolysis of: } \\
\hline \multicolumn{5}{|l|}{ Utilization of: } \\
\hline L-Arabinose & - & - & - & $\mathrm{ND}$ \\
\hline D-Xylose & + & - & + & $\mathrm{ND}$ \\
\hline D-Glucose & + & - & + & $\mathrm{ND}$ \\
\hline D-Fructose & - & - & - & ND \\
\hline Sucrose & + & - & + & ND \\
\hline L-Rhamnose & + & - & - & ND \\
\hline Raffinose & - & - & + & $\mathrm{ND}$ \\
\hline Inositol & - & - & + & ND \\
\hline D-Mannitol & + & + & + & $\mathrm{ND}$ \\
\hline Major cellular fatty acid(s) & iso- $\mathrm{C}_{17: 0}$ & iso- $\mathrm{C}_{17: 0}$ & iso- $\mathrm{C}_{17: 0}$ & $\mathrm{C}_{16: 1} 2-\mathrm{OH}$, iso- $\mathrm{C}_{17: 0}$ \\
\hline
\end{tabular}

*Orn, Ornithine.

$\dagger$ Ara, Arabinose; Gal, galactose; Man, mannose; Rha, rhamnose.

‡DPG, Diphosphatidylglycerol; PG, phosphatidylglycerol; PI, phosphatidylinositol; PIM, phosphatidylinositol mannosides.

from steam-affected geothermal soils in New Zealand (Stott et al., 2008), but these strains have not been described formally. Sequence similarities of 16S rRNA genes among strains $\mathrm{ONI}-1^{\mathrm{T}}$ and $\mathrm{ONI}-5^{\mathrm{T}}$ and the four Chloroflexi bacteria were $96.4-98.1 \%$. Therefore, all strains in the GS cluster may be affiliated with the same genus. However, the level of 16S rRNA gene sequence similarity between strains ONI- $1^{\mathrm{T}}$ and $\mathrm{ONI}-5^{\mathrm{T}}(96.6 \%)$ indicates that these are distinct species, since 16S rRNA gene sequence divergence of more than $3 \%$ is generally regarded as indicative of different species (Stackebrandt \& Goebel, 1994).

There were also phenotypic differences between strains ONI- $1^{\mathrm{T}}$ and ONI- ${ }^{\mathrm{T}}$. Strain ONI- ${ }^{\mathrm{T}}$ grew at $1 \% \mathrm{NaCl}$, but strain ONI $-5^{\mathrm{T}}$ did not. Strain ONI-1 ${ }^{\mathrm{T}}$ was able to utilize glucose, sucrose and rhamnose, while strain ONI- $5^{\mathrm{T}}$ did not grow when these sugars were the sole carbon source. Gelatin was hydrolysed by strain ONI- $1^{\mathrm{T}}$ but not by strain ONI- $5^{\mathrm{T}}$. Strain ONI- $5^{\mathrm{T}}$ developed orange colonies on ISP1 agar, whereas those of strain ONI-1 ${ }^{\mathrm{T}}$ were white.

Overall, the low levels of 16S rRNA gene sequence similarity, together with differences in chemotaxonomic, physiological and biochemical properties, indicate that strains ONI- $1^{\mathrm{T}}$ and ONI-5 ${ }^{\mathrm{T}}$ represent novel species of a new genus, and the names Thermogemmatispora onikobensis gen. nov., sp. nov. and Thermogemmatispora foliorum sp. nov., respectively, are proposed. We also propose the names Thermogemmatisporaceae fam. nov. and Thermogemmatisporales ord. nov. based on the distinct phylogenetic position of Thermogemmatispora within the class Ktedonobacteria. 


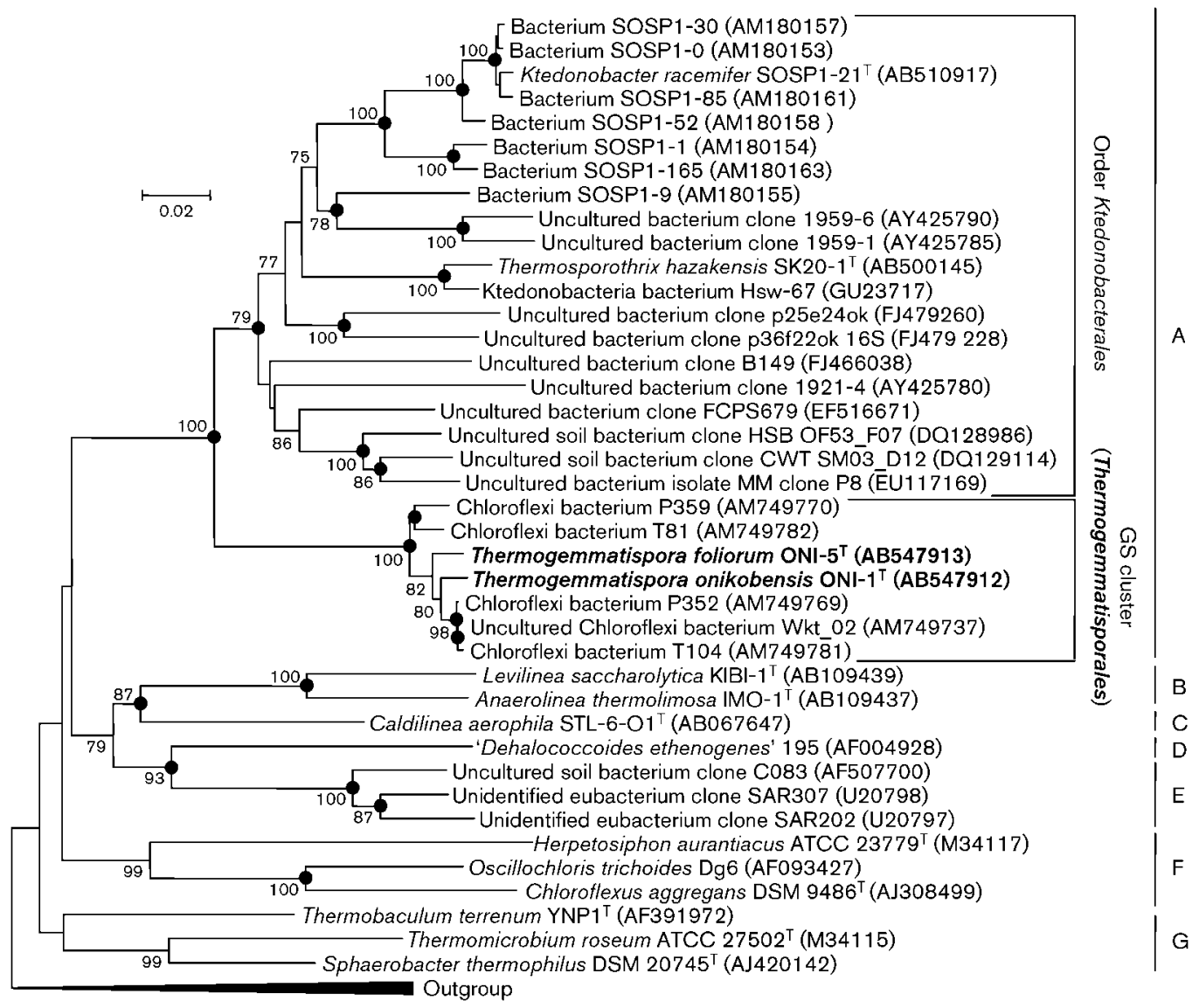

Fig. 2. Neighbour-joining tree based on 1172 aligned positions of the $16 \mathrm{~S}$ rRNA gene sequence. Numbers at nodes are bootstrap percentages from the neighbour-joining method based on 1000 replicated datasets; only values greater than $70 \%$ are shown. Bar, $2 \%$ sequence dissimilarity. The outgroup consisted of sequences from Bacillus subtilis Lactipan (GenBank accession no. AJ277905), Streptomyces arenae ISP 5293 ${ }^{\top}$ (AJ399485), Thermus thermophilus HB8 ${ }^{\top}$ (X07998), Thermotoga maritima MSB-8 ${ }^{\top}$ (M21774) and Aquifex pyrophilus Kol5a ${ }^{\top}$ (M83548). DDBJ/EMBL/GenBank accession numbers are shown in parentheses. Closed circles indicate nodes that were supported by bootstrap values greater than $70 \%$ with the neighbourjoining (Saitou \& Nei, 1987), maximum-likelihood (Felsenstein, 1981) and maximum-parsimony (Fitch, 1971) tree-making algorithms. Classes: A, Ktedonobacteria; B, Anaerolineae; C, Caldilineae; D, 'Dehalococcoidetes'; E, clone cluster; F, Chloroflexi; G, Thermomicrobia.

Although strains ONI-1 ${ }^{\mathrm{T}}$ and $\mathrm{ONI}-5^{\mathrm{T}}$ differ from $K$. racemifer and $T$. hazakensis at the order level, these species have similar morphological features, i.e. formation of branched substrate and aerial mycelia and spores. Therefore, the species belonging to the class Ktedonobacteria may have common morphological features.

\section{Description of Thermogemmatispora gen. nov.}

Thermogemmatispora (Ther'mo.gem.ma'ti.spo'ra. Gr. adj. thermos hot; L. adj. gemmatus provided with buds; Gr. n. spora a seed and, in biology, a spore; N.L. fem. n. Thermogemmatispora thermophilic budding-spored organism).

Filamentous, Gram-stain-positive, spore-forming bacteria. Thermophilic aerobic heterotrophs with glutamic acid, serine, glycine, histidine, alanine and ornithine as peptidoglycan amino acids and rhamnose as a cell-wall sugar. iso$\mathrm{C}_{17: 0}$, iso- $\mathrm{C}_{19: 0}$ and $\mathrm{C}_{20: 0}$ are the major fatty acids and MK$9\left(\mathrm{H}_{2}\right)$ is the major menaquinone. The polar lipids consist of phosphatidylinositol, phosphatidylglycerol and a glycolipid. The type species is Thermogemmatispora onikobensis.

\section{Description of Thermogemmatispora onikobensis sp. nov.}

Thermogemmatispora onikobensis (o.ni.ko.ben'sis. N.L. fem. adj. onikobensis pertaining to Onikobe, named for Onikobe hot springs, the source of the geothermal soils from which the type strain was isolated).

Displays the following properties in addition to those in the genus description. Produces branched vegetative and 
aerial mycelia. Spores are borne in a cluster and are nonmotile, oval in shape $(1.0-2.0 \mu \mathrm{m}$ long and $0.5-1.5 \mu \mathrm{m}$ wide) with rough surfaces. Grows at $50-74{ }^{\circ} \mathrm{C}$ (optimum $60-65{ }^{\circ} \mathrm{C}$ ) and $\mathrm{pH} 4.6-8.0$ (optimum $\mathrm{pH}$ 7.0). Does not require $\mathrm{NaCl}$; growth is inhibited completely by $2 \% \mathrm{NaCl}$. Avicel, CM-cellulose, xylan, chitin and gelatin are hydrolysed, whereas starch and casein are not. Catalase-positive. D-Xylose, D-glucose, sucrose, L-rhamnose and D-mannitol are utilized as sole carbon sources. The $\mathrm{G}+\mathrm{C}$ content of genomic DNA of the type strain is $60.2 \mathrm{~mol} \%$.

The type strain is $\mathrm{ONI}^{-1} \mathrm{~T}^{\mathrm{T}} \quad\left(=\mathrm{JCM} \quad 16817^{\mathrm{T}}=\mathrm{KCTC}\right.$ $\left.19768^{\mathrm{T}}\right)$, isolated from fallen leaves on geothermal soils at Onikobe hot springs, Miyagi, Japan.

\section{Description of Thermogemmatispora foliorum sp. nov.}

Thermogemmatispora foliorum (fo.li.o'rum. L. pl. gen. n. foliorum of leaves, referring to the isolation of the type strain from fallen leaves).

Displays the following properties in addition to those in the genus description. Produces branched vegetative and aerial mycelia. Spores are formed in a cluster and are nonmotile, oval in shape $(1.0-2.0 \mu \mathrm{m}$ long and $0.5-1.5 \mu \mathrm{m}$ wide) with rough surfaces. Grows at $45-74{ }^{\circ} \mathrm{C}$ (optimum 60-65 ${ }^{\circ} \mathrm{C}$ ) and $\mathrm{pH} 4.6-8.0$ (optimum pH 7.0). Does not require $\mathrm{NaCl}$; growth is inhibited completely by $1 \% \mathrm{NaCl}$. Avicel, CM-cellulose, xylan and chitin are hydrolysed, whereas gelatin, starch and casein are not. Catalasepositive. D-Mannitol is utilized as a sole carbon source. The $\mathrm{G}+\mathrm{C}$ content of genomic DNA of the type strain is $58.1 \mathrm{~mol} \%$.

The type strain is $\mathrm{ONI}^{-5^{\mathrm{T}}}\left(=\mathrm{JCM} \quad 16818^{\mathrm{T}}=\mathrm{KCTC}\right.$ $\left.19767^{\mathrm{T}}\right)$, isolated from fallen leaves on geothermal soils at Onikobe hot springs, Miyagi, Japan.

\section{Description of Thermogemmatisporaceae fam. nov.}

Thermogemmatisporaceae (Ther'mo.gem.ma'ti.spo.ra'ce.ae. N.L. fem. $\mathrm{n}$. Thermogemmatispora type genus of the family; -aceae ending to denote a family; N.L. fem. pl. n. Thermogemmatisporaceae the Thermogemmatispora family).

The description is the same as for the genus Thermogemmatispora. The type genus is Thermogemmatispora.

\section{Description of Thermogemmatisporales ord. nov.}

Thermogemmatisporales (Ther'mo.gem.ma'ti.spo.ra'les. N.L. fem. $n$. Thermogemmatispora type genus of the order; -ales ending to denote an order; N.L. fem. pl. n. Thermogemmatisporales the order of the genus Thermogemmatispora).

The description is the same as for the genus Thermogemmatispora. The order contains the family Thermogemmatisporaceae. The type genus is Thermogemmatispora.

\section{Acknowledgements}

Some of this work was partly supported by the Center for Integrated Nanotechnology Support at Tohoku University and also by the 'Nanotechnology Network Project' of the Ministry of Education, Culture, Sports, Science, and Technology (MEXT) of the Japanese Government. We thank Eiji Aoyagi (Institute for Materials Research, Tohoku University) and Kaoru Akiyama (Hanaichi UltraStructure Research Institute) for scanning and transmission electron microscopy and Ms Jee-Young Kim for help with G $+C$ content and cellwall analysis. We acknowledge Professor Dr Jean Euzéby for support with the Latin etymology of the new names. This work was supported in part by a Grant-in-Aid for Promotion of Basic Research by Research Personnel in Private-Sector Business from the Japan Science and Technology Agency (no. b210044).

\section{References}

Cavaletti, L., Monciardini, P., Bamonte, R., Schumann, P., Rohde, M., Sosio, M. \& Donadio, S. (2006). New lineage of filamentous, sporeforming, gram-positive bacteria from soil. Appl Environ Microbiol 72, 4360-4369.

Felsenstein, J. (1981). Evolutionary trees from DNA sequences: a maximum likelihood approach. J Mol Evol 17, 368-376.

Felsenstein, J. (1985). Confidence limits on phylogenies: an approach using the bootstrap. Evolution 39, 783-791.

Fitch, W. M. (1971). Toward defining the course of evolution: minimum change for a specific tree topology. Syst Zool 20, 406416.

Garrity, G. M. \& Holt, J. G. (2001). Phylum BVI. Chloroflexi phy. nov. In Bergey's Manual of Systematic Bacteriology, 2nd edn, vol. 1, p. 427. Edited by D. R. Boone, R. W. Castenholz \& G. M. Garrity. New York: Springer.

Guindon, S. \& Gascuel, O. (2003). A simple, fast, and accurate algorithm to estimate large phylogenies by maximum likelihood. Syst Biol 52, 696-704.

Hall, T. A. (1999). BioEdit: a user-friendly biological sequence alignment editor and analysis program for Windows 95/98/NT. Nucleic Acids Symp Ser 41, 95-98.

Harper, J. J. \& Davis, G. H. G. (1979). Two-dimensional thin-layer chromatography for amino acid analysis of bacterial cell walls. Int J Syst Bacteriol 29, 56-58.

Hugenholtz, P. \& Stackebrandt, E. (2004). Reclassification of Sphaerobacter thermophilus from the subclass Sphaerobacteridae in the phylum Actinobacteria to the class Thermomicrobia (emended description) in the phylum Chloroflexi (emended description). Int J Syst Evol Microbiol 54, 2049-2051.

Kimura, M. (1980). A simple method for estimating evolutionary rates of base substitutions through comparative studies of nucleotide sequences. J Mol Evol 16, 111-120.

Marmur, J. (1961). A procedure for the isolation of deoxyribonucleic acid from micro-organisms. J Mol Biol 3, 208-218.

Morris, R. M., Rappé, M. S., Urbach, E., Connon, S. A. \& Giovannoni, S. J. (2004). Prevalence of the Chloroflexi-related SAR202 bacterioplankton cluster throughout the mesopelagic zone and deep ocean. Appl Environ Microbiol 70, 2836-2842.

Saitou, N. \& Nei, M. (1987). The neighbor-joining method: a new method for reconstructing phylogenetic trees. Mol Biol Evol 4, 406425.

Schleifer, K. H. \& Kandler, O. (1972). Peptidoglycan types of bacterial cell walls and their taxonomic implications. Bacteriol Rev 36, 407-477. 
Shirling, E. B. \& Gottlieb, D. (1966). Methods for characterization of Streptomyces species. Int J Syst Bacteriol 16, 313-340.

Smibert, R. M. \& Krieg, N. L. (1994). Phenotypic characterization. In Methods for General and Molecular Bacteriology, pp. 607-654. Edited by P. Gerhardt, R. G. E. Murray, W. A. Wood \& N. R. Krieg. Washington, DC: American Society for Microbiology.

Stackebrandt, E. \& Goebel, B. M. (1994). Taxonomic note: a place for DNA-DNA reassociation and $16 \mathrm{~S}$ rRNA sequence analysis in the present species definition in bacteriology. Int J Syst Bacteriol 44, 846849.

Stott, M. B., Crowe, M. A., Mountain, B. W., Smirnova, A. V., Hou, S., Alam, M. \& Dunfield, P. F. (2008). Isolation of novel bacteria, including a candidate division, from geothermal soils in New Zealand. Environ Microbiol 10, 2030-2041.

Tamaoka, J. \& Komagata, K. (1984). Determination of DNA base composition by reversed-phase high-performance liquid chromatography. FEMS Microbiol Lett 25, 125-128.

Tamura, K., Dudley, J., Nei, M. \& Kumar, S. (2007). MEGA4: molecular evolutionary genetics analysis (MEGA) software version 4.0. Mol Biol Evol 24, 1596-1599.

Thompson, J. D., Higgins, D. G. \& Gibson, T. J. (1994). CluSTAL W: improving the sensitivity of progressive multiple sequence alignment through sequence weighting, position-specific gap penalties and weight matrix choice. Nucleic Acids Res 22, 4673-4680.
Tindall, B. J. (1990a). A comparative study of the lipid composition of Halobacterium saccharovorum from various sources. Syst Appl Microbiol 13, 128-130.

Tindall, B. J. (1990b). Lipid composition of Halobacterium lacusprofundi. FEMS Microbiol Lett 66, 199-202.

Yabe, S., Aiba, Y., Sakai, Y., Hazaka, M. \& Yokota, A. (2010a). Thermosporothrix hazakensis gen. nov., sp. nov., isolated from compost, description of Thermosporotrichaceae fam. nov. within the class Ktedonobacteria Cavaletti et al. 2007 and emended description of the class Ktedonobacteria. Int J Syst Evol Microbiol 60, 1794-1801.

Yabe, S., Aiba, Y., Sakai, Y., Hazaka, M. \& Yokota, A. (2010b). A life cycle of branched aerial mycelium- and multiple budding sporeforming bacterium Thermosporothrix hazakensis belonging to the phylum Chloroflexi. J Gen Appl Microbiol 56, 137-141.

Yamada, T., Sekiguchi, Y., Hanada, S., Imachi, H., Ohashi, A., Harada, H. \& Kamagata, Y. (2006). Anaerolinea thermolimosa sp. nov., Levilinea saccharolytica gen. nov., sp. nov. and Leptolinea tardivitalis gen. nov., sp. nov., novel filamentous anaerobes, and description of the new classes Anaerolineae classis nov. and Caldilineae classis nov. in the bacterial phylum Chloroflexi. Int $J$ Syst Evol Microbiol 56, 1331-1340.

Yokota, A., Tamura, T., Nishii, T. \& Hasegawa, T. (1993). Kineococcus aurantiacus gen. nov., sp. nov., a new aerobic Gram-positive, motile coccus with meso-diaminopimelic acid and arabinogalactan in the cell wall. Int J Syst Bacteriol 43, 52-57. 